\title{
Perceptions of South African academic instructors toward the teaching and learning of anatomy
}

\author{
L. Lazarus ${ }^{1}$, R. Sookrajh ${ }^{2}$, K.S. Satyapal ${ }^{1}$ \\ ${ }^{1}$ Department of Clinical Anatomy, School of Laboratory Medicine and Medical Sciences, College of Health Sciences, \\ University of KwaZulu-Natal, Westville Campus, Durban, South Africa \\ ${ }^{2}$ Department of Curriculum Studies, School of Education, College of Humanities, University of KwaZulu-Natal, \\ Edgewood Campus, Pinetown, South Africa
}

[Received: 23 August 2018; Accepted: 31 August 2018]

Background: Reflecting on teaching is commonly cited as a fundamental practice for personal and professional development. Educational research into the scholarship of teaching and learning anatomy includes engaging in discipline specific literature on teaching, reflecting on individual teaching methods and communicating these findings to peers. The aim of this paper was to formally assess the opinions of senior anatomy instructors regarding the state of anatomical knowledge at their respective institutions.

Materials and methods: An open-ended questionnaire was devised consisting of eight direct questions seeking opinions on anatomy teaching, knowledge, potential educational developments and general thoughts on the teaching of anatomy to medical students. These were distributed to senior Anatomy Faculty (identified by the author by their affiliation with the Anatomical Society of Southern Africa) based at the eight national medical schools within the country.

Results and Conclusions: A number of key themes emerged. Most senior faculty felt that the standard of medical education at their respective institutions was "good." However, emphasis was also placed on the "quality of teaching" incorporating clinical scenarios. There were also indications that staff are split into those that are keen to do research and those that are happy to provide teaching to medical students as their primary function. Several challenges such as time constraints within the curricula, lack of cadavers to reinforce knowledge and lack of appropriately qualified staff were highlighted. Recommendations included fostering partnerships with both clinicians and medical scientists into the anatomy curriculum thus improving teaching and research. (Folia Morphol 2019; 78, 4: 871-878)

Key words: anatomy, teaching, perceptions, reflection, challenges, curriculum, qualifications

Address for correspondence: Prof. L. Lazarus, Department of Clinical Anatomy, School of Laboratory Medicine and Medical Sciences, College of Health Sciences, University of KwaZulu-Natal, Private Bag X54001, Durban, 4000, South Africa, tel: +27 $312607899 ;+27832751910$, fax: +27 31260 7890, e-mail: ramsaroopl@ukzn.ac.za 


\section{INTRODUCTION}

Anatomy has been the cornerstone of medical education for hundreds of years [14]. However, in the recent past, anatomical teaching has become a remarkably controversial area of medical education [11]. In South Africa, the literature pertaining to anatomical education has focussed on the decline of the discipline in the medical curriculum [31], the clinical relevance of problem-based teaching [5] the relevance of clinical anatomy as the basis for clinical examination [4], the challenges facing medical education in South Africa [23] and the improvement of academic performance of medical students by the implementation of problem-based learning [16].

In addition, South Africa has, in response to international tendencies in higher education, also employed outcomes-based education with the need for student competence as outlined by the recommendations and guidelines of the South African Qualifications Authority (SAQA) [32] and the Health Professions Council of South Africa (HPCSA) [15]. Raubenheimer et al. [30] have recently highlighted the role of the Undergraduate Education and Training Subcommittee of the Medical and Dental Professions Board (HPCSA) in developing core competencies for clinical practice in South Africa in association with the different training institutions and the South African Committee of Medical and Dental Deans. These competencies, when applied to anatomical education, comprise theoretical knowledge of anatomy, having the skill to apply the knowledge three-dimensionally (practically) and being able to apply the knowledge in clinical contexts [30, 32, 33]. However, the HPCSA has not defined a national core anatomy curriculum; thus each University has implemented its own anatomy curriculum. According to Kramer et al. [18], whilst these curricula have some similarities, they also differ markedly from each other. Irrespective of curricular changes, accurate and comprehensive knowledge of anatomy undoubtedly is essential for safe and sound clinical practice $[2,8,15]$. The subject of anatomy is well known to be a discipline that presents most students with a challenge. It is a unique subject in that "it represents a huge set of facts, codified in specialised language" which requires "its own customary approach to teaching and learning" [8]. Anatomical competence involves an in-depth understanding and appreciation of the human body through the ability to assimilate and apply knowledge [2]. According to Smith et al. [35], the teaching of anatomy also has the ability to influence student aptitude, as it would affect the different learning approaches that students adopt. The literature presents us with a polemic relationship between two key perspectives on learning anatomy viz. cadaveric dissection (the traditionalist approach) versus the latest computerised materials (the modernist approach) [27].

In addition, many anatomists and clinicians are of the impression that anatomy is in a state of crisis $[36,38,39]$. This impression has been brought on by a reduction in the number of hours dedicated to anatomy [13], the shortage of cadavers to sustain wet laboratories [10], the lack of gross anatomy teachers and the lack of structured programmes [39].

Since this qualitative study is unique, it is the first in South Africa to investigate professional anatomists' perceptions of anatomical competence of students and teaching methods at their respective institutions as they represent a group of individuals who are committed to their discipline.

\section{MATERIALS AND METHODS}

\section{Design}

This was a descriptive study with a qualitative focus which aimed to glean an understanding of the perceptions of anatomists with regard to their disciplines from the 8 national Medical Schools in South Africa (Table 1).

\section{Sampling}

The researchers chose a small sample for this qualitative inquiry as this enabled us to understand the central phenomena of the study [7]. Lecturers involved in teaching anatomy to health science students were purposively sampled. The number of years of teaching experience ranged from 6 to 40 years. In South Africa health science students comprise medical, nursing, physiotherapy, occupational therapy, speech therapy, dental therapy, oral hygiene, optometry and pharmacy students. Fifteen lecturers agreed to voluntarily participate in the study. Furthermore, two additional clinicians were sampled to validate views regarding anatomical competence. Ethical clearance was obtained from UKZN's Biomedical Research Ethics Committee (BE386/15) and lecturers gave informed consent to participate in the study.

\section{Data collection instruments}

We used open-ended questionnaires to obtain data to gain a real understanding of lecturers' perceptions 
Table 1. Profile of participants $(n=17)$ in the survey conducted

\begin{tabular}{|c|c|c|c|c|c|c|c|c|}
\hline \multirow[t]{2}{*}{ Institutions (number of participants) } & \multicolumn{4}{|c|}{ Qualification } & \multicolumn{4}{|c|}{ Years of experience } \\
\hline & $\mathrm{PhD}$ & MBChB & $\begin{array}{l}\text { MSc/M Med } \\
\text { Science }\end{array}$ & $\begin{array}{l}\text { Teaching } \\
\text { qualification }\end{array}$ & 0-10 & $11-20$ & $21-30$ & $31-40$ \\
\hline Sefako Makgatho Health Sciences University (2) & 0 & 1 & 1 & 0 & 1 & - & - & 1 \\
\hline University of Cape Town (2) & 2 & 0 & 0 & 0 & - & - & - & 2 \\
\hline University of the Free State (1) & 0 & 1 & 0 & 0 & 1 & - & - & - \\
\hline University of KwaZulu-Natal (6) & 2 & 2 & 2 & 0 & 3 & - & 1 & 2 \\
\hline University of Pretoria (1) & 1 & 0 & 0 & 0 & - & 1 & - & - \\
\hline University of Stellenbosch (1) & 1 & 0 & 0 & 0 & - & - & - & 1 \\
\hline University of the Witwatersrand (5) & 3 & 2 & 1 & 1 & 1 & 2 & 2 & - \\
\hline Walter Sisulu University $(0)^{*}$ & - & - & - & - & - & - & - & - \\
\hline Overall (17) & 8 & 6 & 4 & 1 & 6 & 3 & 3 & 5 \\
\hline
\end{tabular}

*There were no respondents from Walter Sisulu University.

Table 2. Schedule of open ended questions for faculty

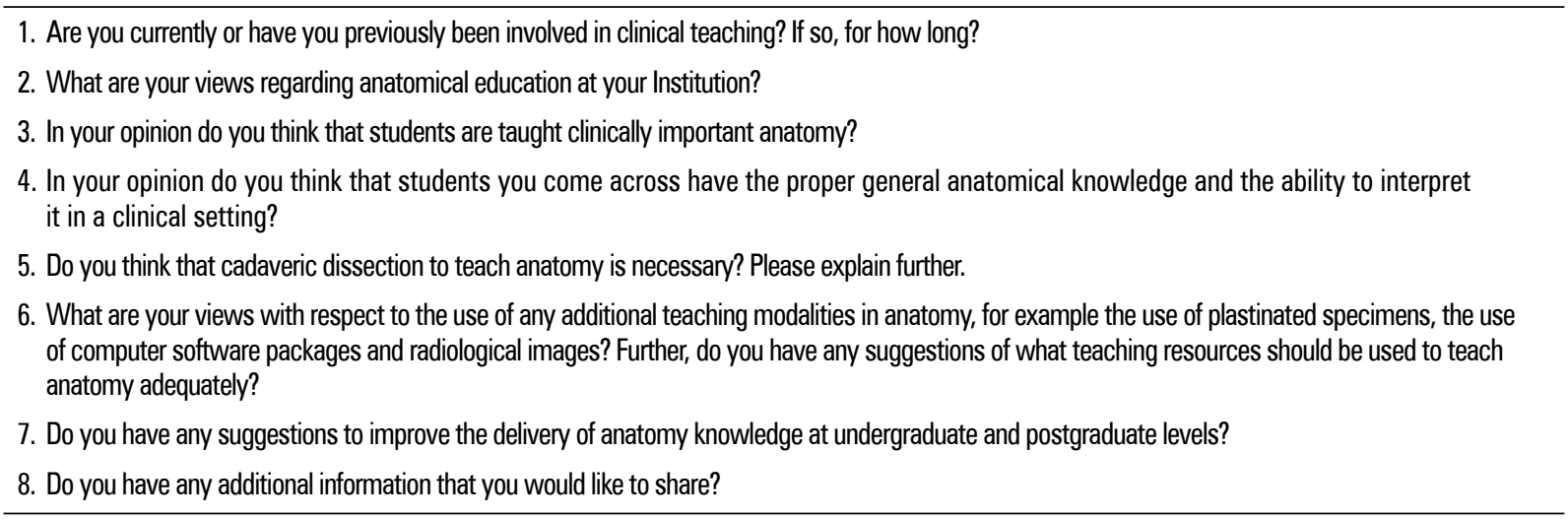

(Table 2). The rationale behind these questions was to allow participants to reflect on their teaching experiences and to provide insight into views regarding student knowledge and teaching methods. The questionnaire was initially piloted on three lecturers; thereafter the researchers decided to add questions for clarity (Questions 6 and 7).

\section{Data analysis}

The researchers used analytical induction [17] to uncover categories within the set of data to derive an understanding of typical perceptions held by instructors. We did this to allow for patterns, themes and categories of analysis to develop from the data [26]. The first author (L.L.) used a colour coding system to organise the data into categories by clustering ideas that pertained to the same concept. In order to validate the data, two other academic staff members who were not involved in anatomy teaching coded the data, thereby ensuring triangulation. According to Denzin and Lincoln [9], triangulation is a procedure that reduces the likelihood of data being misconstrued and involves the combination of two or more investigators within one study to increase the credibility of findings and limits prejudice. The first author then met with the independent reviewers to determine categories from which broad themes were identified and extracted.

\section{RESULTS}

\section{Demographic data}

The sample of this study consisted of a total of 18 participants of whom 9 were male and 9 were female. These participants came from 7 of the 8 national medical schools (Table 1). The highest qualification of the majority of respondents was a Senior Doctorate in 
Medicine (1), PhD (8) with 2 of these also being medically qualified. Qualifications of other staff included MBChB only (4); Master of Science (3) and Master of Medical Science (2). Of these participants, one had a postgraduate qualification in education and training practice. In terms of years of teaching experience, 9 of those surveyed had more than 20 years of experience, whereas only 2 respondents had been teaching for less than 6 years (Table 1).

\section{Thematic analysis}

The recorded data produced two major themes viz. (i) anatomy teaching and resources and (ii) challenges to the teaching and learning of anatomy. Subthemes are further reported within each respective theme.

\section{Theme 1: Anatomy teaching and resources}

Faculty from the various institutions held a dichotomy of opinion with regard to the adequacy of anatomical knowledge and subsequent student competence.

\section{Teaching for practice}

Some anatomists were of the view that excellent teaching of human anatomy was maintained at their Institution.

"We teach students that which they need to know to make them confident practitioners and equip them to be of optimum service to their clients/patients." (Participant 2)

\section{Partnerships with clinicians}

It was suggested that anatomy be taught in an interdisciplinary manner with input from gross anatomists and fostering partnerships with clinicians and not be taught in isolation as is the current status quo.

"It would be good if it (anatomy) could be expanded to relevant clinical problems. It is a time factor but must be considered. I think that anatomy must be taught between anatomists and clinicians (radiologists). Have seminars with multiple disciplines in selected topics, e.g. respiratory disease can have anatomist, pathologist, clinician and radiologist. Can include pharmacology)". (Participant 16)

"Students are taught aspects of anatomy in isolation i.e. histology, embryology and morphological anatomy are taught as separate subjects at some institutions and this hinders the students ability to integrate the knowledge into a clinical setting." (Participant 10)
"Need to interact more with clinicians and involve them in teaching our students in $2^{\text {nd }}$ year." (Participant 7)

Some educators were also of the view that anatomical knowledge was inadequate for practice due to the following reasons such as the subject being taught by non-clinicians.

"Because I think a lot of the anatomy is taught by, or the basic science teaching is by non-clinicians, so I don't think so." (Participant 17)

\section{Integration of basic sciences to clinical application}

Educators also felt the need for the anatomy taught to be clinically relevant as students find it difficult to integrate basic science information applied to clinical scenarios.

"It all bulges down to approach. I must add that Anatomy is first of all a discipline to provide information of the normal structure. The emphasis on 'clinical' Anatomy should be to clearly define when it is presented to a first time student of Anatomy, a student in the clinical years of undergraduate training and a postgraduate student that needs a refresher course in Anatomy for a specialisation degree in any of the clinical disciplines. I want to believe every Anatomy department makes provision for clinically important Anatomy and this will vary from one institution to another within a country and between countries." (Participant 12)

"They struggle to make the connection between the anatomy and a clinical setting. These students are rote learning and it does not help them apply the knowledge they have learnt." (Participant 13)

\section{Resources: cadaveric dissection}

Educators felt that cadaveric dissection was indispensable as it provided a holistic and three-dimensional (3D) appreciation of the human structure and promoted visual-spatial ability.

"Yes, it (cadaveric dissection) is essential - it provides students with a holistic view of the human structure and anatomy as well as gives them the initial skills that will be used during later clinical rotations." (Participant 2)

In addition, educators acknowledged the role of the cadaver in assisting the student to understand humanistic values such as death and dying.

"It (cadaveric dissection) is essential. Gives a 3D perception of the anatomy, which is important for the understanding of anatomical relationships. Helps the student to understand death and cope with the perceptions of dying." (Participant 10) 


\section{Resources: Multimedia, plastinates and imaging}

There was a unanimous consensus among educators that computer software packages, plastinated specimens and radiological images should be used as supplementary teaching modalities and should not replace cadavers.

"3D animations are excellent for teaching. To see one structure on many different views using different modalities is essential for conceptualisation and assimilation of the topic. They are aids and should not replace the experiences and skills gained with dissection of cadavers." (Participant 6)

Some educators expressed concern regarding the accuracy of plastic models.

"Additional modalities are useful in cases where the anatomy is particularly complex, e.g. pterygopalatine fossa. The major problem with models is the level of accuracy in representing the anatomy. Computer based software is nice but it cannot replace the $3 D$ effect of a cadaver." (Participant 10)

\section{Core knowledge}

Some instructors felt that the implementation of the block system and "core topics" contributed to adequate anatomical knowledge.

"We have a list of "core topics" that we cover which was reviewed by Faculty as a whole (including a cohort of clinicians)." (Participant 3)

Some staff also felt that some courses within the curriculum should not be taught with anatomy. They felt that this should be offered later on in training.

"Unfortunately some medical curricula are packed, not with anatomy knowledge necessarily, but with soft skills such as ethics that should be done when basic sciences have concluded." (Participant 6)

\section{Theme 2: Challenges to teaching} and learning of anatomy

Anatomists were at pains to point out some challenges that are not defined by the subject area per se but are general constraints of contemporary medical programmes. Participants consistently highlighted difficulties produced as a result of increased student numbers, reduction in the time devoted to anatomy teaching, inadequately trained staff and the shortage of cadavers.

\section{Increase in student numbers}

"Increased student numbers and a decrease in lectures have made this (teaching) difficult." (Participant 4)

\section{Reduction in anatomy teaching time}

"The general challenge of diminishing anatomy time has precipitated into severe reduction in context and length." (Participant 14)

\section{Staffing}

"More experienced staff required to guide students." (Participant 7)

\section{Shortage of cadavers}

"The lack of cadavers to reinforce knowledge and gain depth perception." (Participant 6)

\section{DISCUSSION}

A review of the available literature, pertaining to anatomical education in South Africa, revealed that there is a dearth of studies associated with the perceptions of staff related to their views regarding anatomy teaching and learning.

Despite the fact that only 18 anatomists participated in the current survey, the results provide us with a snapshot of the current state of medical students' knowledge and understanding of anatomy including the use of different teaching modalities in South Africa from the perspective of their educators. Collectively, the respondents in this study represent the voice of well qualified (9/17 with $\mathrm{PhD}$ qualifications) and experienced medical anatomy educators (6/17 have more than 30 years of experience).

There were opposing views with regard to anatomical competence of students. Some educators felt that students possessed adequate anatomical knowledge whilst others expressed quite vehemently that students did not possess an adequate understanding of the subject for safe and applied clinical practice; the latter perception in this study concurs with the views articulated by Lazarus et al. [19] and Singh et al. [34]. The views expressed by some South African anatomists concur with that of Sugand et al. [37] with regard to the reduction in anatomy teaching time, decreased numbers of sufficiently trained teaching staff and an overall reduction in dissection happening at the medical schools countrywide. The need for more experienced anatomists concurs with that reported by Bergman et al. [3] who stated that it is currently extremely rare for anatomy to be taught by dedicated, well trained, medically qualified gross anatomists. Since non-medical anatomy teachers have a limited understanding of why the subject is relevant from a clinical perspective, the 
decline of medically qualified anatomists are viewed as a peril in students' mastery of anatomical knowledge [29]. In addition, generalist scientists with no formal training or experience in anatomy are being employed by Institutions to teach gross anatomy. Additionally, the criteria governing these appointments are based on the fact that Institutions are employing faculty whose first interest is research to promote research skills and income generation [6]; thus pushing University agendas to "publish or perish" [21] rather than a commitment to teaching. Clinicians are concerned primarily with patient care and even if they are interested in teaching, they are restricted by large workloads [2]. Additionally, universities offer distinctly unattractive salary structures to medically qualified anatomists, thus discouraging faculty with clinical qualifications from taking up teaching positions [25]. The above factors have been implicated as having a negative impact on student's anatomical knowledge, agreeing with Prince et al. [28] and Sugand et al. [37]; thus undermining the importance of human anatomy as a pillar in medical education.

In South Africa, a national core curriculum for anatomical education is non-existent and each University is responsible for its own anatomy curriculum. This creates a wide diversity in the modes of teaching within human anatomy departments with varying emphasis on the different methods individually or in combination [14], resulting in different curricula, different teaching time allocations, staffing numbers and composition. If a core curriculum were in place, both basic and clinical teachers would be cognisant of what students are expected to learn; thus assisting students to achieve that knowledge [2].

This study concurs with Gangata et al. [12] and Bekele et al. [1] who report that $90 \%$ of the medical schools in Africa have retained dissection, despite challenges such as a shortage of cadaveric material for teaching and poor body donor programmes. This study also agrees with Ogunranti [24] who cites a need for change given these challenges of reduced time, appropriately qualified staff and shortages thereof, declining financial allocations by Universities and an increase in student numbers.

Collaborative teaching with clinical staff provided many positive accounts throughout this research. It appeared to be a key point that anatomists consistently brought up to keep teaching grounded in relevant clinical application.
According to Fitzgerald et al. [11] the time spent studying anatomy is worthless without quality teaching resources underpinning it. Traditionally, learning anatomy has been dissection-based [14]. South African anatomists strongly advocate the use of cadaver-based dissection as this modality allows haptic appreciation of 3D anatomy unlike any other teaching facility. They further expressed that learning anatomy on computerised teaching aids, plastinates and imaging were supportive tools and should not replace the cadaver. According to a recent news report [22], the President of the Anatomical Society, stated that using the cadaver also helps with developing the emotional skills of students, something that computer graphics can never replace. She elaborated that, "It is extremely important for any medical or medical-related student to learn the anatomy first hand from a human body; knowledge can never be replaced by computer program or by handbooks. This is leading to huge problems for all of us at medical schools as we do not have enough cadavers to do the training that we need to do."

\section{Limitations of the study}

There are a number of limitations to the current study. Response rates from faculty were poor; no staff from one of the medical schools in the country (Walter Sisulu University) responded to the questionnaire. It is acknowledged that the findings of this study may not be generalisable beyond South Africa. It would be of great interest to examine the views of senior medical students and junior doctors regarding their perceptions of the anatomy that they were taught and how this has impacted in their clinical competence. It would also be simultaneously necessary to ascertain their views on which teaching tools they found beneficial and whether this methodology had in fact perpetuated life-long learning. Strength of the study is that it is unique in that it has for the first time ascertained views via anatomical research in our country and these are not just anecdotal sentiments but rather reports on responses from very senior anatomists.

This study serves to highlight the challenges faced by anatomy educators in South Africa. Core knowledge of anatomy is essential and learning objectives should be the same across Universities whatever teaching approaches are adopted within a curriculum. Faculty consistently indicate the need for human cadaveric dissection as a teaching tool, supplemented 
by a variety of additional resources. The challenge should not be to determine supremacy of one methodology over another; rather to maximise the learning benefit available from the different methods. In summary, we believe this work highlights a clear need for research that addresses not just the learning of anatomy, but also advocates the need for anatomical requirements of cutting edge clinical practice. We invite our colleagues to forward comments and debate our suggestions.

\section{RECOMMENDATIONS AND CONCLUSIONS}

Ideally, the professional accreditation body viz. the HPCSA, in consultation with local medical education societies need to consider a national core curriculum to be adopted by all medical schools countrywide to create standardised norms for the discipline. It is also recommended that clinically relevant teaching that encourages the application of anatomy learning to medical situations, particularly those situations that are commonly encountered by junior doctors, be implemented. As recommended by Bergman et al. [2], it is not inconceivable for anatomists and clinicians to agree upon a core curriculum. Louw et al. [20] highlighted the peculiarities between "general" and "specific" anatomies and how these can be taught using different teaching methods, learning materials and assessment programmes. The development of postgraduate courses in anatomy should be formulated to address the inadequate anatomical knowledge after graduation. Such courses will ensure that early postgraduate training programmes include formal teaching in anatomy. In addition, a review of the formal clinically applied anatomical offerings in postgraduate specialist courses in medicine may be necessary. Staffing issues can be addressed by capacitating current faculty and appointment of only skilled gross or clinical anatomists to be allowed to teach within the discipline. It is recommended that the Anatomical Society of Southern Africa, in consultation with anatomy departments within the country, set up accredited training programmes for anatomists. It goes beyond the scope of this paper to discuss the enhancement of professional recognition, but we would recommend Bergman et al. [2] as a start for anyone interested in further reading.

Integration of the basic sciences such as anatomy with clinical medicine is a challenge that can be overcome by fostering partnerships between clinicians, academics and students by bringing alignment to their perspectives as expressed by Participant 4 in this study:

"I think that we need to diversify the different methods that we employ to deliver our material. Students need regular assessment activities in order to ensure that they master the content and application - Vertical and horizontal integration with other disciplines."

There is a need to interrogate the perceptions of teachers in clinical medicine regarding student competency of applied anatomical concepts in practice through in-depth analyses such as interviews.

\section{Acknowledgements}

The authors wish to thank Dr. A. Nadar for assisting with data analysis and also wish to acknowledge the staff from the various national institutions for their participation in this study.

\section{REFERENCES}

1. Bekele A, Reissig D, Löffler S, et al. Experiences with dissection courses in human anatomy: a comparison between Germany and Ethiopia. Ann Anat. 2011; 193(2): 163-167, doi: 10.1016/j. aanat.2010.10.007, indexed in Pubmed: 21167695.

2. Bergman EM, van der Vleuten CPM, Scherpbier AJ. Why don't they know enough about anatomy? A narrative review. Med Teach. 2011; 33(5): 403-409, doi: 10.3109/ 0142159X.2010.536276, indexed in Pubmed: 21355704.

3. Bergman EM, Verheijen IWH, Scherpbier AJ, et al. Influences on anatomical knowledge: The complete arguments. Clin Anat. 2014; 27(3): 296-303, doi: 10.1002/ca.22341, indexed in Pubmed: 24357119.

4. Boon JM, Meiring JH, Richards PA, et al. Evaluation of clinical relevance of problem-oriented teaching in undergraduate anatomy at the University of Pretoria. Surg Radiol Anat. 2001; 23(1): 57-60, indexed in Pubmed: 11370144.

5. Boon JM, Meiring JH, Richards PA. Clinical anatomy as the basis for clinical examination: development and evaluation of an Introduction to Clinical Examination in a problem-oriented medical curriculum. Clin Anat. 2002; 15(1): 45-50, doi: 10.1002/ca.1091, indexed in Pubmed: 11835544.

6. Cahill DR, Leonard RJ, Marks SC. A comment on recent teaching of human anatomy in the United States. Surg Radiol Anat. 2000; 22(2): 69-71, indexed in Pubmed: 10959670.

7. Creswell JW. Qualitative inquiry and research design: Choosing among five approaches. Sage. 2013.

8. de Bere SR, Mattick K. From anatomical 'competence' to complex capability. The views and experiences of UK tutors on how we should teach anatomy to medical students. Adv Health Sci Educ Theory Pract. 2010; 15(4): 573-585, doi: 10.1007/ s10459-010-9220-0, indexed in Pubmed: 20140495.

9. Denzin NK, Lincoln YS. The SAGE handbook of qualitative research. Sage. 2011: Apr 27.

10. Du Toit DF. Ethics, litigation and teaching of anatomy. South African Med J. 2008; 93(12): 878. 
11. Fitzgerald JEF, White MJ, Tang SW, et al. Are we teaching sufficient anatomy at medical school? The opinions of newly qualified doctors. Clin Anat. 2008; 21(7): 718-724, doi: 10.1002/ca.20662, indexed in Pubmed: 18773486.

12. Gangata $H, N$ taba $P, A k o l P$, et al. The reliance on unclaimed cadavers for anatomical teaching by medical schools in Africa. Anat Sci Educ. 2010; 3(4): 174-183, doi: 10.1002/ ase.157, indexed in Pubmed: 20544835.

13. Hassanzadeh G, Hassanpoor N, Jalali A, et al. Teaching Anatomy: Viewpoints of Iranian Anatomists. Thrita J Med Sci. 2012; 1(2): 62-66, doi: 10.5812/thrita.6434.

14. Hegazy AMS. Reflection of the type of medical curriculum on its anatomy content: trial to improve the anatomy learning outcomes. Int J Clin Devel Anat. 2015; 1(3): 52, doi: 10.11648/j.ijcda.20150103.11.

15. HPCSA. Core competencies for undergraduate students in clinical associate, dentistry and medical teaching and learning programmes in South Africa. Developed by the Undergraduate Education and Training Subcommittee of the Medical and Dental Professions Board in collaboration with training institutions and the South African Committee of Medical and Dental Deans. 2014. http://www.hpcsa. co.za/uploads/editor/UserFiles/MDB\%20Core\%20Competencies\%20-\%20ENGLISH\%20-\%20FINAL\%202014. pdf (Accessed 12 September 2016).

16. Iputo JE, Kwizera E. Problem-based learning improves the academic performance of medical students in South Africa. Med Educ. 2005; 39(4): 388-393, doi: 10.1111/j.13652929.2005.02106.x, indexed in Pubmed: 15813761.

17. Katz J. Analytic induction. In International encyclopaedia of the social and behavioural sciences. Elsevier Science Ltd., Amsterdam Smelser NJ Baltes PB 2001.

18. Kramer B, Pather N, Ihunwo AO. Anatomy: spotlight on Africa. Anat Sci Educ. 2008; 1(3): 111-118, doi: 10.1002/ ase.28, indexed in Pubmed: 19177392.

19. Lazarus MD, Chinchilli VM, Leong SL, et al. Perceptions of anatomy: critical components in the clinical setting. Anat Sci Educ. 2012; 5(4): 187-199, doi: 10.1002/ase.1281, indexed in Pubmed: 22532497.

20. Louw G, Eizenberg N, Carmichael SW. The place of anatomy in medical education: AMEE Guide no 41. Med Teach. 2009; 31(5): 373-386, indexed in Pubmed: 19811128.

21. Monkhouse WS, Farrell TB. Tomorrow's doctors: today's mistakes? Clin Anat. 1999; 12(2): 131-134, doi: 10.1002/ (SICI) 1098-2353(1999)12:2<131::AID-CA9>3.0.CO;2-L, indexed in Pubmed: 10089040.

22. Mothibi M. Shortage of cadavers at SA universities. 2015. http://www.sabc.co.za/news/a/c15ba3004978726 8a0cda1623266b54e/Shortage-of-cadavers-at-SA-universities (Accessed 14 September 2016).

23. Ncayiyana D. Medical education challenges in South Africa. Med Educ. 1999; 33(10): 713-715, indexed in Pubmed: 10583759.

24. Ogunranti JO. Challenges and prospects of anatomy in the 21 st century. In6th scientific conference-anatomical society of Nigeria, Ahmadu Bello University Zaria-16th October 2008.
25. Older J. Anatomy: A must for teaching the next generation. Surgeon. 2004; 2(2): 79-90, doi: 10.1016/s1479666x(04)80050-7.

26. Patton MQ. Qualitative research and evaluation methods. Thousands Oaks, Sage 2000.

27. Pereira JA, Pleguezuelos E, Merí A, et al. Effectiveness of using blended learning strategies for teaching and learning human anatomy. Med Educ. 2007; 41(2): 189-195, doi: 10.1111/j.1365-2929.2006.02672.x, indexed in Pubmed: 17269953.

28. Prince KJ, Scherpbier AJ, van Mameren $H$, et al. Do students have sufficient knowledge of clinical anatomy? Med Educ. 2005; 39(3): 326-332, doi: 10.1111/j.13652929.2005.02096.x, indexed in Pubmed: 15733169.

29. Raftery A. Anatomy teaching in the UK. Surgery (Oxford). 2007; 25(1): 1-2, doi: 10.1016/j.mpsur.2006.11.002.

30. Raubenheimer $D$, Raubenheimer JE, van Zyl S. A scoring framework for assessing anatomy competence of undergraduate preclinical students. Anat Sci Educ. 2016; 9(4): 319-329, doi: 10.1002/ase.1585, indexed in Pubmed: 26588194.

31. Satyapal KS, Henneberg M. Anatomy into the next millennium: quo vadis, or simply where to? Clin Anat. 1997; 10(1): 41-3; discussion 44, doi: 10.1002/(SICl)10982353(1997) 10:1<41::AID-CA7>3.0.CO;2-W, indexed in Pubmed: 8986387.

32. SAQA. South African Qualifications Authority. Developing learning programme for NQF- registered qualifications and unit standards. A step-by-step guide. 2005. 1st ed. Pretoria. Gauteng. South Africa: South African Qualifications Authority p 48. http://www.saqa.org.za/docs/guide/2005/ dlp.pdf(Accessed 21 September 2016).

33. Schoeman S, Chandratilake M. The anatomy competence score: a new marker for anatomical ability. Anat Sci Educ. 2012; 5(1): 33-40, doi: 10.1002/ase.263, indexed in Pubmed: 22127894

34. Singh R, Tubbs RS, Gupta K, et al. Is the decline of human anatomy hazardous to medical education/profession? A review. Surg Radiol Anat. 2015; 37(10): 1257-1265, doi: 10.1007/s00276-015-1507-7.

35. Smith CF, Martinez-Álvarez C, McHanwell S. The context of learning anatomy: does it make a difference? J Anat. 2014; 224(3): 270-278, doi: 10.1111/joa.12089, indexed in Pubmed: 23930933.

36. Staśkiewicz GJ, Walczak $\mathrm{E}$, Torres $\mathrm{K}$, et al. What do clinicians think of the anatomical knowledge of medical students? Results of a survey. Folia Morphol. 2007; 66(2): 138-142, indexed in Pubmed: 17594673.

37. Sugand $K$, Abrahams $P$, Khurana $A$. The anatomy of anatomy: a review for its modernization. Anat Sci Educ. 2010; 3(2): 83-93, doi: 10.1002/ase.139, indexed in Pubmed: 20205265.

38. Waterston SW, Stewart IJ. Survey of clinicians' attitudes to the anatomical teaching and knowledge of medical students. Clin Anat. 2005; 18(5): 380-384, doi: 10.1002/ ca.20101, indexed in Pubmed: 15971223.

39. Yammine $K$. The current status of anatomy knowledge: where are we now? Where do we need to go and how do we get there? Teach Learn Med. 2014; 26(2): 184-188, doi: 10.108 0/10401334.2014.883985, indexed in Pubmed: 24702556. 